\title{
Keterlibatan Orang Tua dalam Pendidikan Seksualitas Anak
}

\author{
ChlaraSinta Duri Kartika ${ }^{1}$, Abdul Kadir ${ }^{2}$, Ndaru Putri Yudhiarti ${ }^{3}$, Septina Nur Istiqamah ${ }^{4}$, \\ Firda Shafira ${ }^{5}$, Eny Purwandari ${ }^{6}$ \\ University Muhammadiyah Surakarta \\ kadirsahlan781@gmail.com.
}

\begin{abstract}
ABSTRAK
Pemenuhan pendidikan seksual anak-anak masih diabaikan, pendidikan seks untuk anak-anak dilihat sebagai sesuatu yang negatif dan masih sulit untuk disampaikan kepada anak-anak. Orang tua memiliki peran penting dalam pendidikan seksual anak-anak karena orang tua adalah guru pertama untuk anak. Maka itulah alasannya, perlu ada upaya untuk memberikan penjelasan kepada anak-anak tentang fungsi organ seksual mereka. Untuk mendapatkan pemahaman yang komprehensif, maka dilakukan survei terhadap 80 orang tua, di salah satu sekolah dasar di Sragen. Penelitian ini menggunakan Pendekatan kualitatif dengan metode fenimenologi. Untuk mendapatkan data peneliti menggunakan kuesioner terbuka.
\end{abstract}

Kata kunci: Peran Orang Tua, Pendidikan, Seksualitas Anak

\section{ABSTRACT}

The fulfillment of children sexual education is still ignore, the sex education for children is watched as something negative and still dificult to be educated to children.The parents has an important role for the children sexual education because the parents is the first teacher for the children. So that is the reason, there should have an effort to give an explaination to the children about the function of their sexual organs.To get komperhensive understanding, it was done survey towards 80 parents, in one of Elementary school in Sragen.This reseach used kualitatif approach with fenimenology methode. To get the data the researcher used open questionair.

Keywords: Parent's role, Education, Children sexuality

\section{PENDAHULUAN}

Terkait dengan peran orang tua dalam komunikasi seksualitas dengan anak, penelitian (Lestari, 2007) mengungkapkan bahwa sikap ibu dalam komunikasi seksualitas dengan anak dapat dikategorikan menjadi: (1) memberikan penjelasan, (2) bingung dalam menjawab pertanyaan anak, (3) melarang anak untuk bertanya, (4) menunda jawaban dan menganggap anak akan tahu sendiri, dan (5) mengalihkan topik pembicaraan. Bila dilihat dari proporsinya masih lebih banyak ibu yang tidak memberikan penjelasan terhadap pertanyaan tentang seksualitas yang diajukan oleh anak daripada yang bersedia memberikan penjelasan. Kondisi tersebut dapat menjadi pendorong bagi anak untukmencari tahu sendiri dari sumber-sumberlain yang memungkinkan untuk mengaksesnya (Lestari, 2013)
Penelitian Lestari,

(2011) mengungkapkan bahwa teman sebaya menjadi sumber informasi yang paling banyak dipilih oleh remaja laki-laki maupun remaja perempuan. Bila dicermati lebih lanjut terdapat perbedaan antara remaja lakilaki dan perempuan dalam memilih sumber informasi tentang seks. Remaja perempuan memilih teman $(41,6 \%)$ sebagai sumber pertama, berikutnya adalah orangtua $(14,2 \%)$, buku $(6,9 \%)$, internet $(6,5 \%)$, guru dan media $(3,4 \%)$, kakak $(2,7 \%)$, dan ahli $(2,3 \%)$. Pada remaja laki-laki pilihan untuk urutan pertama sumber informasi tentang seks juga teman, namun urutan berikutnya yang menonjol adalah internet. Urutan berikutnya adalah guru $(8,6 \%)$, media dan buku (masing-masing $3,3 \%)$, orangtua $(1,9 \%)$, ahli $(1,5 \%)$ dan kakak $(0.7 \%)$. Pemilihan orangtua sebagai sumber informasi seks pada remaja perempuan relatif 
kecil, namun bila dibandingkan dengan pemilihan remaja laki-laki, remaja perempuan masih memiliki motivasi yang lebih besar daripada remaja laki-laki untuk mencari informasi tentang seks dari orangtua.

Peneltian yang dilakukan Kim,(2007) Selain dari sisi anak, hambatan dalam komunikasi seksualitas juga dapat berasal dari sisi orang tua Seperti terungkap dalam penelitian orangtua dari keluarga Asia Amerika memilih mengomunikasikan nilainilai seksualitas pada anak secara implisit dan nonverbal.

Sedangkan hasil penelitian Lestari, (2013) Komunikasi seksualitas orang tuaanak berperan penting dalam memberikan bekal informasi seksualitas pada anak dan membentuk perilaku seksual yang bertanggungjawab pada anak. Komunikasi seksualitas tersebut sebaiknya menekankan pentingnya nilai-nilai moral terkait seksualitas sebagaimana yang telah diajarkan dalam agama. Kelebihan komunikasi seksualitas orang tua-anak dibandingkan sumber informasi seksualitas lainnya adalah terjaminnya kesinambungan komunikasi yang terjadi antara orang tuaanak. Mengingat pentingnya peran orang tua sebagai pemberi informasi seksualitas bagi anak, sebaiknya orang tua menjalankan peran tersebut dengan baik agar anak tidak memenuhi rasa ingin tahunya tentang seksualitas ke sumber-sumber lain yang tidak dapat dipertanggungjawabkan kebenarannya. Terungkap bahwa komunikasi seksualitas yang terjalin antara orang tua dengan anak masih rendah. Bahkan masih ditemukan orang tua yang merasa tidak perlu membekali anak dengan pengetahuan seksualitas karena memandang anak akan tahu sendiri bila sudah besar.(Lestari S. , 2010)

Sedangkan hasil penelitian Kerry,(2017) Mayoritas orang tua beanggapan bahwa pendidikan seksualitas pada anak sekolah dasar itu relevan dan penting. Pendidikan seksualitas seharusnya diberikan secara kolaboratif antara pihak sekolah dan keluarga. Namun beberapa keluarga mengakui bahwa sejauh ini beberapa topic terkait pendidikan seksual hanya bisa diberikan dirumah.

Jennifer, (2017) Komunikasi keluarga tentang seks bisa melindungi remaja dari perilaku berisiko, seperti seks dini dan seks tanpa pengaman. sementara tidak ada perbedaan kelompok yang ditemukan untuk tanggapan terhadap orang tua sudut pandang Temuan studi menyoroti pentingnya seks program pendidikan yang mendukung seksualitas remaja komunikasi, terutama bagi siswa sekolah menengah.

Kesimpulannya, ada sejumlah aspek dan faktor (misalnya, sosio-ekonomi, genetik, psikologis, pendidikan, perkembangan, intraindividu, antar individu) yang dapat mempengaruhi keefektifan / keberhasilan program pendidikan seksual apare ntal sehubungan dengan Kesehatan seksual optimal anak-anak mereka. Banyak faktor ini serta hubungan di antara mereka masih memerlukan penyelidikan ilmiah yang cukup besar. Karena Pendidikan Seksualitas nampaknya merupakan konsep multi dimensi, kami menganggap bahwa pendekatan multidimensional dan interdisipliner serupa harus dilakukan saat merancang, menerapkan dan menafsirkan hasil dari program pendidikan seksual orang tua ( Meda, 2015)

Hasil penelitian menunjukkan bahwa ada korelasi positif yang signifikan secara statistik antara tingkat perfeksionisme dan perfeksionisme seksual secara global.Hasil ini penting karena ada penelitian yang mengaitkan dimensi tertentu atau bentuk perfeksionisme maladaptif dengan faktor kerentanan psikopatologi. Mereka dapat membantu dalam menetapkan arah dan tingkat intervensi untuk mengelola kerentanan ini, mencegah atau mengurangi tekanan psikologis dan disfungsionalitas atau hanya mengembangkan potensi seseorang.(Meda,2015)

Orangtua melaporkan peningkatan pemahaman tentang kurikulum pendidikan seksual dan kesadaran akan buku anak-anak yang relevan, meningkatkan interaksi dengan anak-anak mereka mengenai topik pendidkan seksual dan beberapa efek positif pada pasangan dan sikap terhadap sekolah. Ada peningkatan kepercayaan diri dalam menangani masalah dalam kurikulum pendidikan seksual untuk orang tua yang berusia 8 sampai 10 tahun.

Hasil penelitian menunjukkan, dari sisi pendidikan dan pekerjaan, orangtua cukup berpotensi untuk banyak terlibat dalam pengasuhan anak. Keterlibatan orangtua baik di TK maupun di rumah sudah cukup baik, namun perlu ditingkatkan khususnya dalam melatih kemandirian keseharian anak di rumah dan kesediaan menjadi relawan di TK. Oleh karena itu perlu dipikirkan strategi yang sesuai agar orangtua lebih terlibat dalam pendidikan anaknya

Ada sejumlah besar anak sekolah yang melaporkan peningkatan pengetahuan 
kesehatan seksual di sekolah eksperimental. Hal ini menunjukkan bahwa fasilitator kesehatan memimpin program pendidikan seks lebih efektif dalam meningkatkan pengetahuan kesehatan seksual anak-anak sekolah. (Amini, 2015 )

\section{Tujuan dan Manfaat}

Tujuan kegiatan pengabdiaan yang diikuti oleh 124 orang tua atau selaku wali murid siswa kelas 5 SD Muhammadiyah Sragen ini adalah untuk: (1) Meningkatkan pengetahuan dalam memberikan edukasi mengenai seks pada anak yang sesuai, efektif dan efisien (2) memberi pemahaman bahwa pendidikan seks bukanlah hal yang tabu tetapi sebagai bentuk pembelajaran yang bersifat preventif agar anak bisa secara mandiri melindungi bagian personalnya.

Adapun manfaat yang didapatkan peserta dari mengikuti kegiatan ini antara lain: (1) Mempermudah orang tua dalam memberikan penjelasan yang berkualitas dan benar kepada anak tentang pendidikan seks; (2) ikut memanfaatkan dengan tepat hadirnya teknologi canggih seperti gadget dan fasilitas internet yang mendukung sebagai media pembelajaran untuk mencari referensi terkait; (3) bisa berperan sebagai fasilitator anak dengan memberikan rasa aman, nyaman dan menyenangkan ketika anak bertanya tentang pendidikan seks.

METODE KEGIATAN
Mitra atau sasaran kegiatan
pengabdian ini ialah orang tua atau wali
murid SD Muhammdiyah Sragen. Jumlah
orang tua yang terlibat sebanyak 124 orang
tua. Tahapan kegiatan pengabdian ini
mulai dari persiapan hingga kesimpulan
dan sasaran yang selanjutnya mengikuti
alur proses kerja sebagaimana
digambarkan pada gambar dibawah ini
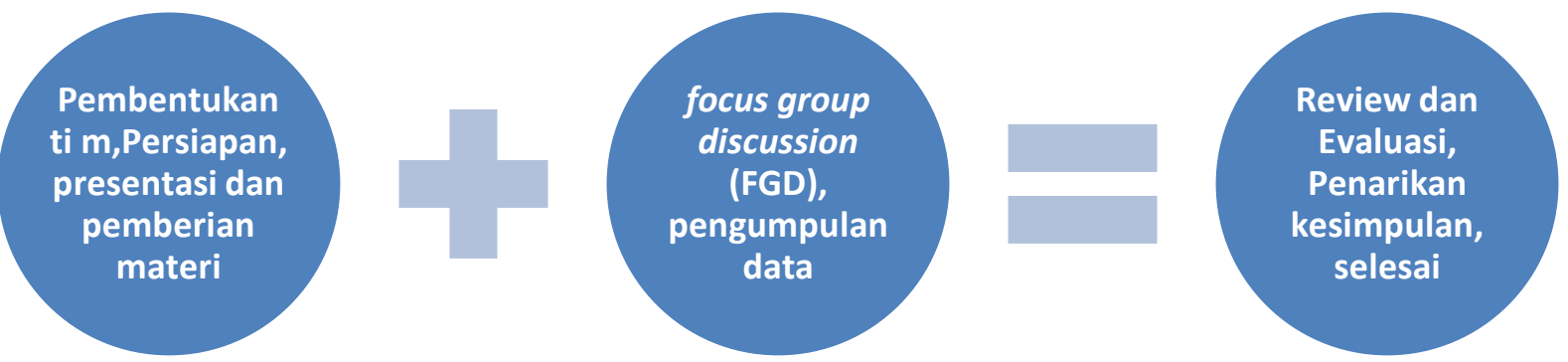

Gambar 1. Alur kerja kegiatan pengabdian masyarakat

Kegiatan pengabdian ini diawali dengan pembentukan tim pelaksana yang terdiri dari dosen dan mahasiswa mahasiswi Sekolah Pascasarjana Program Magister Psikologi Universitas Muhammadiyah Surakarta. Setelah tim pelaksana terbentuk, maka persiapan selanjutnya menentukan materi yang akan dibawakan sesuai tema yang diangkat, materi tersebut nantinya akan dibawakan oleh pengisi materi dengan cara dipresentasikan oleh salah satu mahasiswa dengan durasi 20 menit. Kegiatan ini diadakan pada tanggal 27 Januari 2018 bertempat di Gedung PMI Kabupaten Sragen, Jawa Tengah.

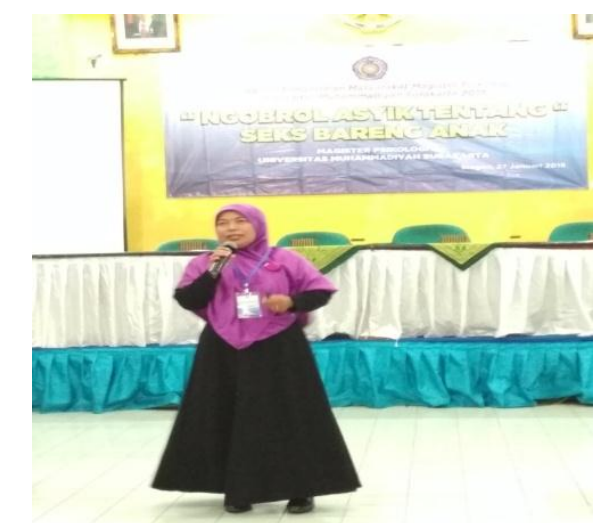

Gambar. 2 Presentasi dilakukan di depan wali murid

Setelah diberi materi, masing-masing peserta dibentuk dalam kelompok-kelompok kecil yang berisikan 10-12 orang didalamnya dan kelompok tersebut didampingi oleh satu fasilitator. Fasilitator membuka forum FGD dan membagikan angket yang berisikan 
pertanyaan yang gunanya untuk mengambil data dialam kelompok dan meminta orang tua untuk menjawab pertanyaan tersebut. Diskusi kelompok antar orang tua akan dipandu oleh fasilitator. Setelah sesi diskusi selesai fasilitator akan menarik kesimpulan besar dari hasil diskusi yang sudah dibahas.

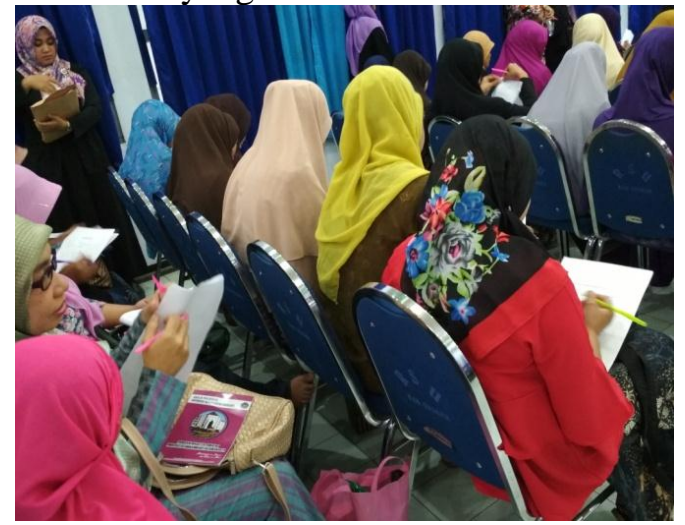

Gambar 3. Suasana saat pengisian lembar

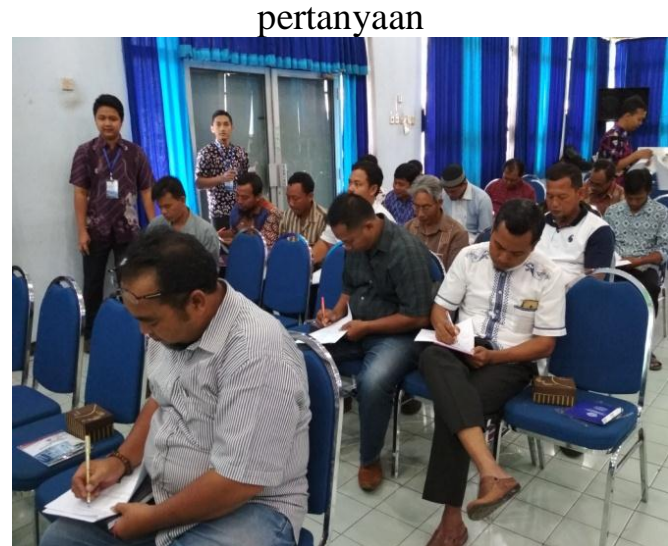

Gambar 4. Suasana saat pengisian lembar pernyataan

Setelah kegiatan inti selesai, di akhir sesi pengisi acara mengajukan beberapa pertanyaan rebutan yang ditujukan kepada semua peserta, hal ini dilakukan dengan tujuan seberapa besar antusias para peserta mengikuti kegiatan peserta yang bisa menjawab pertanyaan dengan tepat, lugas dan benar akan mendapat predikat peserta terbaik dan hadiah. Selain itu Kaprodi Magister Psikologi Universitas Muhammadiyah Surakarta juga menyerahkan kenang-kenangan kepada pihak SDN Muhammadiyah Sragen sebagai tanda terima kasih atas kerjasama pelaksanaan kegiatan pengabdian masyarakat.

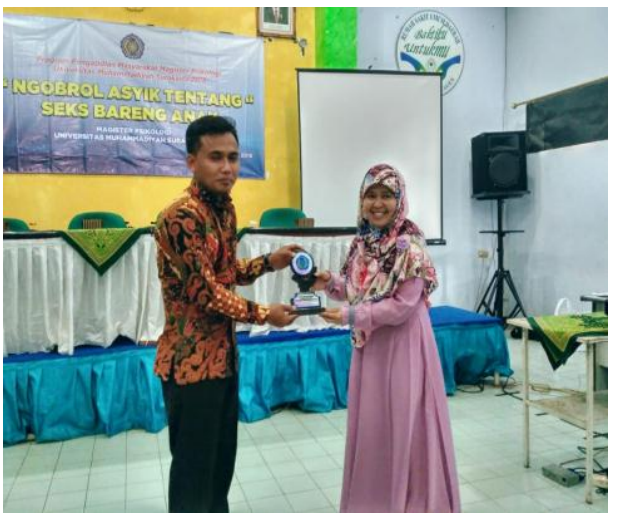

Gambar 5. Penyerahan kenang-kenangan

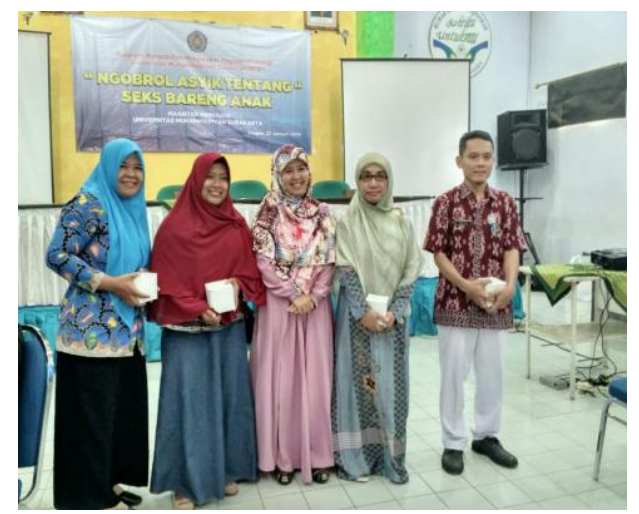

Gambar 6. Peserta terbaik berfoto bersama Kaprodi

Penelitian ini merupakan bagian dari kualitatif dengan metode deskriptif tentang keterlibatang orang tua dalam pendidikan seksualitas anak. Oleh karena itu penelitian ini menggunakan angket dengan pertanyaan terbuka. Model petanyaan terbuka dipilih agar dapat memahami pandangan responden tentang seksualitas anak. Salah satu bagian dari angket bertujuan mengungkap keterlibatan orang tua dalam mendidik seksualitas pada anak. Pertanyaan yang di ajukan kepada responden tentang hal tersebut adalah (1) Apa yang anda ketahui tentang pendidikan seks untuk anak? (2) Ketika anak menanyakan hal berkaitan dengan seks, anak lebih sering bertanya pada ayah atau ibu? (3) Bagaimana cara anda menjelaskan perbedaan seksualitas antara anak laki-laki dengan anak perempuan? (4) Bagaimana cara anda menjelaskan perbedaan seksualitas antara anak laki-laki dengan anak perempuan?

Data dianalisis dengan menggunakan teknik analisis statistik yang sederhana dengan yakni statistik deskriptif terutama perhitungan frekuensi dan tabulasi. Data yang dianalisis didasarkan pada jumlah responden, yang dikategorikan berdasarkan isi respon yang muncul. validitas dari penelitian ini menggunakan member cek. 


\section{HASIL \& PEMBAHASAN}

Secara etimologi, Istilah seksualitas belum ada padanan katanya dalam bahasa Indonesia, seksualitas berasal dari kata seks, yang berarti cirri-ciri anatomi biologi yang membedakan antara lelaki dan perempuan. Namun demikian, terma seksualitas dengan maknanya yang kompleks secara historis baru muncul pada awal abad ke-18. Seksualitas dimaknai sebagai konstruksi sosial tentang pengetahuan, norma, dan perilaku serta subjektivitas yang berkaitan dengan seks dan terkait erat dengan sistem kekuasaan pengetahuan. Seksualitas mencakup nilai atau norma, aturan-aturan, yang memberikan status dan peran, yang membatasi dan mengatur perilaku atau tindakam yang berkaitan dengan seks. Makna seksualitas adalah bagaimana suatu masyarakat memberikan arti terhadap pengalaman seksual yang secara nyata ada di masyarakat. Pemaknaan subjektif tidak dapat terlepas dari sistem kekuasaan yang memperkuat atau bahkan melegitimasi konstruksi pengetahuan, norma, dan perilaku seksualitas. Kebudayaan juga memiliki peran dalam penentuan makna seksualitas, yaitu kapan seseorang dapat memulai aktivitas

seksual dan kapan menghentikannya, termasuk bagaimana mengekspresikannya. Seksualitas memiliki makna lebih luas dan mencakup tidak hanya seks, tapi juga gender dan persoalan relasi kuasa. Perbedaan paling penting antara seksualitas dengan seks dan gender terletak pada objek materialnya. Jika seks berkaitan dengan aspek fisik anatomic biologis, gender berhubungan dengan konstruksi sosial, dan seksualitas kompleksitas dari keduanya. Seks mendefinisikan jenis kelamin fisik hanya pada jenis laki-laki dan perempuan dengan pendekatan anatomis, sedangkan seksualitas merupakan konstruksi sosial terhadap entitas seks yang mengatur bodily functions (Rohmaniyah, 2017).

Olson \& Defrain (dalam Khaerani, 2013) menyatakan bahwa seksualitas merupakan aspek penting dalam kehidupan manusia, kesehatan, dan kebahagiaan. Seksualitas meliputi jenis kelamin, identitas dan peran gender, orientasi seksual, erotisme, kesenangan, keintiman, dan reproduksi. Seksualitas dialami dan diekspresikan dalam pikiran, fantasi, keinginan, kepercayaan, sikap, nila-nilai, perilaku, prakttek, peran, dan hubungan. Seksualitas dipengaruhi oleh interaksi niologis, psikologis, sosial, ekonomi, politik, budaya, etika, hukum, sejarah, agama, dan spiritual. Begitu banyak aspek yang mempengaruhi seksualitas namun tidak banyak yang mengungkap hal ini.

Sementara pengetahuan orang tua mengenai pendidikan seks untuk anak cukup mengetahuinya sebagai mana tabel di bawah ini :

Tabel 1 : Pengetahuan tentang pendidikan seks untuk anak

\begin{tabular}{|c|c|c|}
\hline Kategori & Frequensi & $\%$ \\
\hline Batasan Pergaulan & 19 & 23.75 \\
\hline Pemahaman Menjaga Diri & 17 & 21.25 \\
\hline Perbedaan Karakteristik Fisik Lk Dan Pr & 16 & 20 \\
\hline Pendidikan Ilmiah Dan Agama & 6 & 7.5 \\
\hline Hubungan Lawan Jenis & 4 & 5 \\
\hline Hal Yang Tabu & 4 & 5 \\
\hline Batasan Aurat & 3 & 3.75 \\
\hline Dalasan Aurat . & 3 & 3.75 \\
\hline Pendidikan Akhil Baliqh & 3 & 3.75 \\
\hline Belum Tahu & & \\
\hline Tidak Menjawab & 3 & 3.75 \\
\hline Pentingnya Pendidikan Seks & 2 & 2.5 \\
\hline Jumlah & 80 & 100 \\
\hline
\end{tabular}


Tabel 2 : Apakah anda pernah menjelaskan pendidikan seks pada anak

\begin{tabular}{lccc}
\hline & Kategori & Frequensi & \% \\
\hline Pernah & 46 & 57.5 \\
Belum & 26 & 32.5 \\
Tidak Menjawab & 8 & 10 \\
\hline Jumlah & 80 & 100 \\
\hline
\end{tabular}

Tabel 3 : Bila pernah, bagaimana caranya?Bila belum, kenapa?

\begin{tabular}{lcc}
\hline \multicolumn{1}{c}{ Kategori } & Frequensi & \% \\
\hline Dengan cara menjelaskan & 21 & 26.25 \\
Cara diskusi & 12 & 15 \\
Belum waktunya & 9 & 11.25 \\
Belum mengetahui & 8 & 10 \\
Penjelasan melaui media & 7 & 8.75 \\
Tidak menjawab & 7 & 8.75 \\
Belum pernah & 5 & 6.25 \\
Cara mendongeng & 4 & 5 \\
Cara bercerita & 4 & 5 \\
Anak tidak bertanya & 3 & 3.75 \\
Tidak paham dengan bahasa anak & 3 & 3.75 \\
& 1 & 1.25 \\
\hline Jumlah & 80 & 100 \\
\hline
\end{tabular}

Tabel 4 : Ketika anak menanyakan hal berkaitan dengan seks, anak lebih sering bertanya pada ayah atau ibu?

\begin{tabular}{lccc}
\hline & Kategori & Frequensi & \% \\
\hline Ibu & 57 & 71.25 \\
Tidak jawab & 11 & 13.75 \\
Keduanya & 7 & 8.75 \\
Ayah & 5 & 6.25 \\
& & \\
\hline Jumlah & 80 & 100 \\
\hline
\end{tabular}

Tabel 5 : Jelaskan alasan anda?

\begin{tabular}{lcc}
\hline \multicolumn{1}{c}{ Kategori } & Frequensi & \% \\
\hline Kedekatan dengan ayah/ibu & 60 & 75 \\
Tidak menjawab & 15 & 18.75 \\
Persamaan gender ayah/ibu & 3 & 3.75 \\
Perbedaan karakteristik fisik & 1 & 1.25 \\
Anak tidak bertanya & 1 & 1.25 \\
\hline Jumlah & 80 & 100 \\
\hline
\end{tabular}


Tabel 6 : Bagaimana cara anda menjelaskan perbedaan seksualitas antara anak laki-laki dengan anak

\begin{tabular}{|c|c|c|}
\hline \multicolumn{3}{|c|}{ perempuan } \\
\hline Kategori & Frequensi & $\%$ \\
\hline Menjelaskan ciri fisik & 20 & 23.75 \\
\hline Tidak menjawab & 16 & 20 \\
\hline Melalui media & 12 & 15 \\
\hline Fungsi organ reproduksi & 10 & 12.5 \\
\hline Belum menjelaskan & 5 & 6.25 \\
\hline Menjelaskan perbedaan perilaku & 5 & 6.25 \\
\hline Menjelaskan dengan pendekatan agama & 4 & 5 \\
\hline Dijelaskan disekolah & 3 & 3.75 \\
\hline $\begin{array}{l}\text { Menjelaskan perbedaan sifat laki-laki dan } \\
\text { perempuan }\end{array}$ & 2 & 2.5 \\
\hline Menjelaskan batasan pergaulan & 1 & 1.25 \\
\hline Menjelaskan cara berpakaian & 1 & 1.25 \\
\hline Menjelaskan dampak perilaku & 1 & 1.25 \\
\hline
\end{tabular}

Jumlah

KESIMPULAN \& SARAN

Secara keseluruhan kegiatan pengabdian masyarakat yang diadakan oleh sekolah pascasarjana Magister Psikologi Universitas Muhammadiyah Surakarta bekerjasama dengan SDN Muhammadiyah Sragen berjalan lancar sesuai rencana yang diharapkan . Latar belakang pekerjaan serta usia dan pendidikan menjadikan adanya beragam data yang diperoleh. Animo yang besar kedatangan orang tua dalam kegiatan pengabdian masyarakat tersebut menjadi cerminan bahwasanya orang tua memiliki rasa curiousity tentang tema yang diusung dikarenakan hal tersebut berhubungan langsung dengan anak-anak yang notabene masih berada di usia belia. Para orang tua juga mengharapkan kegiatan-kegiatan sejenis dapat diadakan lagi dengan tema yang terkini sebagai sarana pembelajaran.

Diharapkan setelah selesai kegiatan ini para orang tua bisa menyampaikan, meluruskan dan mengaplikasikan langsung dalam kehidupan sehari-hari terkait dengan pendidikan seks yang selama ini masih banyak kesalahpahaman atau menganggap itu sesuatu yang "memalukan". Selain itu, diharapkan orang tua tidak bosan untuk mencari referensi yang disertai dengan penjelasan ilmiah bukan sekedar pendapat sendiri atau asumsi yang bisa menyebabkan salah kaprah. Buatlah diskusi yang menyenangkan bersama anak melalui media bacaan baik cetak maupun elektronik agar anak bisa mencerna dengan mudah.

\section{DAFTAR PUSTAKA}

Alimmuha, M. (2013, April ). Melindungi Anak dari Konten Negatif Internet. Studi terhadap peramban Web Khusus Anak, SAWWA, p. Vol. 8 no 2 .

Amini, $\quad$ M. (2015 ). PROFIL KETERLIBATAN ORANG TUA DALAM PENDIDIKAN ANAK USIA TK. journal international, Vol. 10 no 1.

Jennifer, G. (2017). "We Talked About Sex."“No, We Didn't": Exploring Parent Agreement About Sexuality Communication. International Journal , Vol. 0,1-15.

Kerry, R. (2017). Responsibilities, tensions and ways forward: parents' perspectives on children's sexuality education. International Journal Sex Eduacation, Vol. 12-27.

Kim, J. L. (2007). Silence speaks volumes: Parental sexual communication among. Journal of Adolescent Research, Vol. 22, 3-31. DOI: 10.1177/0743558406294916. 
Lestari, S. \&. (2007). Sikap ibu terhadap pertanyaan anak tentang seksualitas. Psikologika, Vol. 12, 147-155.

Lestari, S. (2010). Youth courtship sexual behavior, exposure to pornography, and parental sexual communication. Anima, Vol. 25 (4),257-264.

Lestari, S. (2013). KOMUNIKASI SEKSUALITAS ORANG TUAANAK BERBASIS NILAI. Prosiding Seminar Nasional Parenting. Solo .

Lestari, S. S. (2011). Identifikasi kebutuhan informasi seksualitas pada remaja . Jurnal Ilmiah Psikologi, Vol. 5 (2), 180-188.

Meda V. Popa, A. S. (2015). Satisfaction and Communication in Couples of Parents and Potential Parents - Psychological Predictors and Implications for Sexuality. Interational Journal ScienceDirect, Vol 402-410.

Meda V. Popa, A. S. (2015). The Role of Parents in Shaping and Improving the Sexual Health of Children - Lines of Developing Parental Sexuality Education Programmes. International Journal, Vol. 395-401. 